\title{
APPLYING PROFESSIONAL METHODS OF TEAM FEEDBACK TO IMPROVE TEAMWORK IN AN INTERDISCIPLINARY PROJECT-BASED UPPER- LEVEL DESIGN COURSE
}

\author{
John ANDERSON and Stacy BENJAMIN \\ Segal Design Institute, Northwestern University
}

\begin{abstract}
We present an approach for coaching design team members to give qualitative feedback to each other in an upper-level undergraduate design project course. Giving and receiving feedback is an essential part of effective teamwork. However, students sometimes struggle to give sufficiently precise and actionable feedback. We find that using the BET/BEAR models from Harms and Roebuck [1] helps students give both praise and criticism in a form that is specific and results oriented. The models allow us to reinforce general principles about effective teamwork; they are simple to explain, easy to apply, and relevant to a wide range of team and project types. In the past, we have required students to submit their BET and BEAR feedback using spreadsheet templates; we have introduced a web-based version of the assignment that makes it easier for students to exchange feedback more frequently and more easily. We discuss what we have learned from using these models in our courses over time and offer examples from a word frequency analysis of past responses, as well as survey responses from former students. We also offer practical suggestions for incorporating these models into team-based, projectbased design courses.
\end{abstract}

Keywords: Teamwork, feedback, qualitative, interdisciplinary, design

\section{INTRODUCTION}

At the start of our interdisciplinary upper-level undergraduate design course sequence, we tell the students that their team is similar to a product development team at a design consulting firm. Students work in small teams on open-ended design projects, each with a different external client. The projects last approximately twenty weeks, spanning two academic quarters. The course is taught within the engineering school but is open to third thru fifth year students of any discipline who have completed a prerequisite introductory course on user-centred design. The class tends to be roughly two-thirds engineering students and one-third from other disciplines. Our objective is for students to manage their own teams to the greatest extent possible. Not only must the teams demonstrate steady progress towards a solution, they must also reflect at intervals on their own design process, share their evaluations with us, and work together to improve their communication and teamwork.

Each student is required to give their teammates both positive and negative feedback on a regular basis, using the BET (behaviour, effect, thanks) and BEAR (behaviour, effect, alternative, result) feedback models described in Harms and Roebuck [1]. Both models start with a specific description of a teammate's behaviour (B) and its effect (E) on the team's performance. A BET concludes with a thankyou (T), while a BEAR goes on to propose alternatives (A) to the behaviour, as well as the expected results $(\mathrm{R})$ of changing their behaviour. Students are prompted to exchange BET and BEAR feedback at several points during their design project.

We have been mostly satisfied with our use of the BET/BEAR models. The faculty review the feedback and find it useful when assessing both the productivity of a team, and the engagement of an individual student.

Current students frequently cite the experience of giving and receiving feedback as part of an end-ofcourse written reflection on teamwork and ethics, indicating that while they are in the class, at least, they see the connections between the regular exchange of feedback and their team's success. 
However, we have started to investigate other ways of evaluating and improving our use of the BET/BEAR models. We have begun to analyse the collected responses (recorded since 2011) to investigate trends across teams, sections, and years. We have also begun reaching out to former students, seeking to supplement the impressions gathered from students still in the course with those of alumni, in order to learn more about what elements of lasting value students take away from these assignments. Both of these enquiries are still in their early stages; we report some of our initial findings here.

In addition, we have made changes to streamline and simplify the process of submitting feedback responses, in order both to lessen our own administrative burdens, and to make the tool significantly easier to use. These innovations are also new; we look forward to comparing in more detail the results gathered under the old system, based on spreadsheet templates, with those gathered using the new webbased tool.

\section{BET/BEAR AS A PEER FEEDBACK TOOL IN DESIGN EDUCATION}

There is a vast literature on peer feedback in higher education, particularly engineering education, and much attention devoted to peer feedback in design courses [2, 3, 4, 5]. However, it is important to note that the type and purpose of feedback we are discussing is only one subtype of peer response, both when compared to the literature and to peer response activities in our own course. Carberry et al. [5] note in passing that "team contributions in senior capstone design courses" is only one of a number of types and occasions for peer feedback in the engineering curriculum. It is this type of peer feedback with which our present inquiries are primarily concerned.

In our view, which is the view promoted by Harms and Roebuck, "feedback" has a larger goal than peerevaluation of a specific assignment. Harms and Roebuck use the model of a performance review, where employees discuss their objectives and achievements with a supervisor. The goal is not only to assess particular milestones, but to foster a general positive trend. So too with peer feedback among members of a design team. While the BET/BEAR framework requires focus on specific behaviours and outcomes, which lets teams address specific issues, another goal of giving feedback is to help the recipient improve their overall ability to contribute to this team, and perhaps also to future teams. Harms and Roebuck state that "[f]eedback aligns workplace behaviour with the overall goals of a team or an organisation" [1]. One reason why we find the BET/BEAR models useful for our course is that the teams are in a situation where they genuinely need them: they are meeting regularly, planning their work, and organising themselves. Our students may not yet be full-fledged design professionals, but they must act like ones if they are to harness the full creativity of their teams. We find the BET/BEAR models not only convenient but appropriate, oriented as they are towards the continuing productivity of the team and the improvement of its members.

We therefore find it somewhat surprising that Harms and Roebuck have not been more widely or approvingly cited in the engineering education literature. Verleger et al. [6] dismiss Harms and Roebuck in passing, grouping it with other examples and asserting that they "train students to give feedback using an overly-structured approach." However, the grounds for their objections, with regard to the BET/BEAR models, are not explained. Their study, while interesting, describes a different peer feedback scenario, focused on improving a specific response to a specific design challenge and procedure draft. While the authors are doubtless correct to discard Harms and Roebuck as unsuited to their purposes, the value of the BET/BEAR models in different team scenarios remains an open question. Wolfe [7] notes that Harms and Roebuck "describe teaching business communication students to provide feedback to teammates by stating specifically how a teammate's behaviour makes them feel," but does so in the context of an argument regarding gender and communication in the workplace; the merits of the specific approach proposed by Harms and Roebuck is not discussed. Again, while the topic under discussion in Wolfe is fascinating, it is different from ours.

Fredrick [8] highlights the need for effective coaching from instructors in teamwork, noting that students are often "unable to consciously harness or transfer past productive strategies to make teamwork more effective and/or efficient." We suggest that the BET/BEAR models can be used to make the process more conscious, in part by specifying and naming effective teamwork behaviours.

Frederick goes on to state that "[e]ffective self-evaluations should ask students not only to catalogue their contributions to the team but also to analyse their styles of interaction and the strategies they plan to employ in future team settings." We agree.

While the BET/BEAR models are useful, they have limitations. We would like to draw closer connections between students' conscious efforts to improve their teamwork, and their team's eventual 
success on their project, but we are unable to do so, yet, except anecdotally. Neumeyer and McKenna [3] offer a model applied in their study of entrepreneurial student teams that is impressively thorough. However, it is a very different tool, developed to answer different questions with a higher degree of precision.

The BET/BEAR framework is lean, minimal, and modular. It can be used in conversation; it is a sequence of simple steps that are not dependent on software. The advantage of recording one's responses is that one can preserve them for future reflection, but the essence of the framework is a method: to name and describe a specific act, to describe and explain its effects, and then either to express gratitude, or to go on to describe an alternative to the original behaviour and a reason to consider it.

\section{PRELIMINARY FINDINGS FROM WORD FREQUENCY ANALYSIS OF ARCHIVED RESPONSES}

We used CATMA [9] to analyse the text of the BET-BEAR comments from the 2011-12 academic year through 2017-18, beginning with word frequency to understand what general topics were most discussed. A total of 3307 BET and 2667 BEAR responses were analysed. The most frequent word was "meeting" and its variations, followed by "idea."

Articles were ignored, as were words that appeared frequently, but had little real significance (e.g., team, group, work, thank, project). Two words, "time" and "design," required special consideration. Although both words had many usages that were meaningful, they also had a high number of generic uses, such as "last time," "next time," and "design project." Since the meaningful uses tended to be aligned with other high-frequency topics, "time" and "design" were also ignored.

Table 1. Word frequency analysis, BET/BEAR responses AY 2011-12 through AY 2017-18

\begin{tabular}{|l|r|}
\hline Word & Count \\
\hline Meeting(s) & 2,996 \\
\hline Idea(s) & 1,367 \\
\hline Communicate (and variations) & 662 \\
\hline Assignments & 540 \\
\hline
\end{tabular}

The highest frequency word stems included: meeting, idea, communicate, and assignment (Table 1). Looking at the context around these words showed they were spread across both the BET and the BEAR comments in recognition of things that went well or were helpful, as well as problem areas. We also used the word context to identify sub-topics, and then analysed the frequency of these sub-topics using collocation queries.

The most common comments on meetings related to productivity and focus. These were mixed across positive and negative feedback, ranging from appreciation for a team member's role in organising and leading meetings that are productive and efficient, to observations that the teammate is often distracted, on their phone, or takes the team off-topic. The second most common topic was lateness or missed meetings. This was sometimes connected to the idea of efficiency, in that starting late or having to repeat content made for less efficient sessions. The remaining topics about meetings were more spread out in terms of frequency, and included things like attitude, being prepared, speaking up, and sharing or critiquing ideas.

The main sub-topic with the idea comments was around getting more, new, and different ideas. This could be related to thanking a teammate for having so many ideas, their bringing a unique perspective and ideas to the project, or about being careful not to kill ideas too early or discouraging others from contributing. A second significant sub-topic was about communicating ideas. This generally included an appreciation of someone's sketching ability, the value of the sketches and visualisations, skill in explaining ideas to the team or professors, encouraging others to speak up more about their ideas, or again, cautioning teammates in how they critique ideas.

Most comments around communication related to inter-team communication, especially around scheduling meetings and managing assignments, but also around sharing information and ideas as noted above. There were some mentions of communicating progress to the professors and to the client.

The positive comments on assignments related to someone taking the lead on, volunteering for, or tracking and organising assignments. In the BEAR category, students provided feedback on assignments being done at the last minute, being rushed, or being late, and encouraging more team communication. 


\section{STUDENT EVALUATIONS OF THE MODELS: A SUMMARY OF SURVEY RESULTS}

To determine whether students take lasting value from the BET/BEAR assignments, we sent a survey to 280 former students who took our course between AY 2011-12 and AY 2017-18, the same period for which we have archived BET/BEAR responses. There were 33 respondents. The survey included a total of 11 questions related to how the students used the exercises, what value the exercises did or did not provide, and suggestions for change. The questions included a mix of multiple choice and open-ended formats. We present a brief excerpt of some of the most interesting responses here. When asked "What was your general opinion of these exercises?" the majority found the exercises to be valuable, as shown below (Table 2), though not overwhelming so.

Table 2. General opinion of the exercises, survey of past students (33 respondents)

\begin{tabular}{|l|r|l|}
\hline Question & \multicolumn{1}{|c|}{ Totals } & Answer selected \\
\hline $\begin{array}{l}\text { What was your } \\
\text { general opinion of } \\
\text { these exercises? }\end{array}$ & 14 & I found these valuable and appreciated getting the feedback \\
\cline { 2 - 3 } & 10 & I thought they were somewhat interesting, but not that valuable \\
\cline { 2 - 3 } & 9 & I didn't think they provided enough value to be worth the time they took \\
\hline
\end{tabular}

Table 3. Reflection on the value of giving and receiving comments, survey of past students (29 respondents)

\begin{tabular}{|l|r|l|}
\hline Question & Totals & Comments \\
\hline $\begin{array}{l}\text { What (if any) } \\
\text { value did you get } \\
\text { from writing } \\
\text { comments for } \\
\text { your teammates }\end{array}$ & 25 & Described value of assignment \\
\cline { 2 - 3 } & 3 & Expressed annoyance with assignment \\
\hline \multirow{2}{*}{$\begin{array}{l}\text { What (if any) } \\
\text { value did you get } \\
\text { from the } \\
\text { comments you } \\
\text { received? }\end{array}$} & 10 & Did not remember the assignment \\
\cline { 2 - 3 } & 5 & Appreciated understanding how others perceive them \\
\cline { 2 - 3 } & 4 & Took action to address points raised by feedback \\
\cline { 2 - 3 } & 4 & Was reassured that they were doing a good job \\
\cline { 2 - 3 } & 4 & Did not receive any value from the exercise \\
\hline
\end{tabular}

The most interesting part of the survey was really the free responses to the following questions, summarised in Table 3: "What (if any) value did you get from writing comments for your teammates?" and "What (if any) value did you get from the comments you received?" In these comments, the students expressed more benefit in writing the comments than they did in receiving them.

Of those who answered, 25 of the 29 described some value they received from writing comments for their teammates, while only three of the respondents indicated annoyance at having to do the exercises, and one claimed not to remember. This is in contrast to how they responded to the general question described above, suggesting that students' negative response might have more to do with the time involved than the quality of the exercise itself.

As expected, a significant number of students (nine), mentioned that they used the feedback to raise issues and identify ways for their teammates to improve. An equal number of students said that the exercises helped them to reflect on the team dynamic, team roles, and individual contributions overall, and two more students explicitly mentioned that it made them think about their own role as a member of the team. One student commented that it "helped me be reminded to have an attitude of caring for my teammates rather than seeing them as a means to a successful project" and another said "it forced me to put my feelings into words..." There were two students who talked about it being a valuable professional skill. 
The same 29 students responded to the question about the value of receiving feedback. Ten of the respondents made general statements about it being useful to get feedback on their work, and three students mentioned that they were reassured that they were doing a good job. Five students commented more specifically on the value in understanding how others perceive them. Only four students mentioned taking actions to address the feedback. There were also four students who wrote that they didn't remember receiving any meaningful comments, and another four said they did not receive any value from the exercise.

The comments for change included a broad range of feedback, some pertaining to the class in general rather than the teamwork exercises. Most of the comments on the teamwork exercises related to simplifying the process, changing the timing of the exercises, including more open-ended options, and requiring group discussion.

\section{RECENT CHANGES TO OUR ADMINISTRATION OF THE FEEDBACK ASSIGNMENTS AND THEIR EFFECTS}

The BET/BEAR models have been used to create a web-based submission form. Team members can $\log$ in at any time during the course to give feedback, or review feedback received. The largest changes we have made in developing the web-based tool have been to remove anonymity and faculty moderation. Before, students' comments were reviewed by faculty before being forwarded to the recipient with the name of the original giver removed. There are two reasons for this change. First, on small teams, it is not difficult to deduce the origin of a comment, making anonymity difficulty to preserve. Second, this moderation is time consuming, requiring students to wait both for all of their teammates to complete the assignment, and for the instructor to moderate the feedback. The new online system is not only easier to administer, freeing up the attention of the former moderator for other work, but also imposes a shorter delay before students can receive feedback.

One purpose of faculty moderation was to prevent incomplete, frivolous, or abusive feedback. In practice, faculty intervention was very rarely necessary, and never to prevent an inappropriate comment. However, we did introduce three features into the new version of the online tool to prevent the unlikely event of a mistaken or untoward response. First, there is a two-hour delay before a posted response can be read by its recipient. Second, the giver can hide, but not edit or delete, a response they have given. The function of the first two features is to allow the giver of a response to withdraw a hasty, hurtful, or ungrammatical statement, while maintaining the integrity of the record. Hidden comments are visible only to the giver, the instructors, and the system administrators; the latter two may delete or edit the response. Third, instructors or recipients can also flag a response, which gives recipients the ability to express their disapproval of a comment they find objectionable.

In practice, the flag and hide functions have been used exactly zero times so far. They remain as safeguards, but so far it appears that students are thinking before they give a comment and are not taking offense when they receive one.

The administrative burden of the assignment has been automated and reduced. The faculty no longer need to download spreadsheet files, cut and paste collections of responses, remove identifying information, and forward the comments to individual students. For the cost of writing and testing a few lines of code, hosting a simple web application, and making regular database backups, we have greatly reduced our administrative workload. Both students and instructors now have a tool they can use when they wish, and do not have to wait for an administrator to deliver the results.

However, to be useful over the long term, it must be able to be supported by others as a routine part of their regular duties, with no special pampering required. Three things have been done to ensure this outcome. First, the online tool has been built using software packages that are commonly available, widely used, well-respected, and open source. Second, user authentication is handled through the same system used to validate logins for other campus systems: users do not need to create and maintain a new account to use the tool. Third, all users of the tool have the ability to export their own data - the responses they, or their students, have given and received - as a .csv file for their own use. These three facts make it more likely that, first, the current tool can be maintained with minimal attention in its current form; second, that it can be ported to a different platform, and thus more easily maintained by a different team of administrators, if that becomes necessary or desirable; and third, that the information recorded by the system will not be held hostage to a specific software and hardware configuration. 


\section{CONCLUSIONS}

All of our inquiries are currently in a preliminary stage. We have collected the archived responses generated by our design teams over the past eight years and put them in a form that can be analysed systematically. We plan to extend our surveys of both current and former students. In addition, at the end of this year we will have a body of responses generated under the new web-based feedback system that we will then be able to compare to the older dataset. We will then be able to ask new questions about our students' use of the models and their assessment of its value: for example, comparing the frequency of responses, the distribution and number of comments among members of a team, and the variation in length between BET and BEAR responses.

However, even in advance of more systematic questioning, we have indications that students are using the new tool in ways that address some of the flaws or drawbacks identified by our former students: namely, to make it feel less like an assignment, and more like a conversation. For example, one team using the new web-based tool noted that, while the online method got them started, they preferred to put it aside after the first round of feedback, and give their comments to each other in a meeting, face-toface. They followed the same steps outlined on the website but avoided using screen-based communication because they had become comfortable enough to speak honestly to each other, so much so that using only the online tool seemed, in their words, "passive-aggressive." This outcome was unexpected, and we will need to investigate what incentives we should give teams to continue preserving their responses using the tool, but the instructors have only praise for these students' understanding and application of the BET and BEAR models. The point of the assignment is not to fill out a web form: that is the least important step in the process. The point is to give more constructive feedback by making that feedback more specific and results-oriented.

\section{REFERENCES}

[1] Harms P.L. and Roebuck D.B. Teaching the Art and Craft of Giving and Receiving Feedback, Business Communication Quarterly, 2010, 73(4), 413-431.

[2] Hirsch P.L. and McKenna A. Using reflection to promote teamwork understanding in engineering design education, International Journal of Engineering Education, 2008, 24(2), $377-$ 385 .

[3] Neumeyer X. and McKenna A. Entrepreneurial Thinking in Interdisciplinary Student Teams, Advances in Engineering Education, 2016, 5(1). Available: https://eric.ed.gov/?id=EJ1090585 [Accessed 14 November 2018].

[4] van der Pol J., van den Berg B.A.M., Admiraal W.F. and Simons P.R.J. The nature, reception, and use of online peer feedback in higher education, Computers \& Education, 2008, 51(4), 18041817.

[5] Carberry A., Brunhaver S., Csavina K.R. and McKenna A. Comparison of written versus verbal peer feedback for design projects, International Journal of Engineering Education, 2016, 32(3), 1458-1471.

[6] Verleger M.A., Rodgers K.J. and Diefes-Dux H.A. Selecting Effective Examples to Train Students for Peer Review of Open-Ended Problem Solutions, Journal of Engineering Education, 2016, 105(4), 585-604.

[7] Wolfe J. Extended Abstract: Challenging the Common Wisdom of 'I-messages' in Conflict Management: Lessons from Female Engineers, 2018, IEEE International Professional Communication Conference (ProComm), 65-66.

[8] Fredrick T.A. Facilitating Better Teamwork: Analysing the Challenges and Strategies of Classroom-Based Collaboration, Business Communication Quarterly, 2008, 71(4), 439-455.

[9] Meister J.C., Petris M., Gius E. and Jacke J. CATMA 5.0, 2016 [software for text annotation and analysis]. Available: http://catma.de/ [Accessed 11 March 2019]. 